\title{
Effects of maintaining intravenous infusion of remifentanil or propofol on anesthesia and palinesthesia during anesthesia and analepsia
}

\author{
X. Zhao ${ }^{1 *}$, Y.W. Jin ${ }^{1 *}$, H.B. Li ${ }^{2}$, Z.G. Wang ${ }^{3}$, H. Feng ${ }^{1}$ and C. Feng ${ }^{1}$ \\ ${ }^{1}$ Department of Anesthesiology, Second Hospital of Shandong University, \\ Jinan, China \\ ${ }^{2}$ Jinan Central Hospital Operating Room Affiliated to Shandong University, \\ Jinan, China \\ ${ }^{3}$ Department of Anesthesiology, Shandong University Qilu Hospital, \\ Jinan, China \\ *These authors contributed equally to this study. \\ Corresponding author: X. Zhao \\ E-mail: lujnzx@sohu.com
}

Genet. Mol. Res. 13 (2): 2865-2872 (2014)

Received July 8, 2013

Accepted December 12, 2013

Published February 13, 2014

DOI http://dx.doi.org/10.4238/2014.February.13.8

\begin{abstract}
When recovering from general anesthesia, upon removal of the endotracheal tube, patients may experience a high dynamic response in the circulatory system, along with choking and restlessness. This study was designed to study the effect of maintaining an intravenous infusion of remifentanil or propofol on the performance of general anesthesia, including on the cardiovascular response, choking and irritability at the end of general anesthesia. We treated 60 patients with combined inhalation and general anesthesia for lower esophageal cancer resection. When the surgery was complete, narcotic drug treatment ceased, oropharynx and endotracheal suctioning was performed with a simple breathing bag, and the patient was quickly
\end{abstract}


sent to the anesthesia recovery room. In the recovery room, patients were randomly divided into three groups $(\mathrm{N}=20)$ : the control group (waiting for extubation), the remifentanil group (target-controlled infusion of remifentanil; the target plasma concentration was $3 \mathrm{ng} /$ $\mathrm{mL}$ ) and the propofol group (target-controlled infusion of propofol; the target plasma concentration was $2 \mu \mathrm{g} / \mathrm{mL}$ ). The results show that maintaining an intravenous infusion of remifentanil or propofol can reduce the hemodynamic response, choking and irritability observed at the end of palinesthesia after administration of general anesthesia upon removing the endotracheal tube. The patients in the remifentanil group were fully awake when extubating, and remifentanil intervention did not extend the recovery time. Therefore, a maintenance infusion of remifentanil during general anesthesia may be a better choice.

Key words: Opioid analgesic; Remifentanil; Propofol; Palinesthesia; General anesthesia; Post-surgery

\section{INTRODUCTION}

Palinesthesia after anesthesia and removal of the endotracheal tube can stimulate the trachea, which can cause high blood pressure, tachycardia, bucking, increased intraabdominal and intracranial pressure, myocardial ischemia, and arrhythmias (Leech et al., 1974; Plafreman and Wakeling, 2002; Irwin, 2006). This is especially common in patients with obesity, hypertension, or cardiovascular disease, and can lead to fatal consequences. In order to prevent the highly dynamic response and choking during the extubation period after general anesthesia, many methods such as deep anesthesia extubation, the use of local anesthetics, vasodilators, short-acting opioid drugs, and other methods have been used in the clinic (Hohlrieder et al., 2007). Propofol, an intravenous anesthetic commonly used in the clinic, has a good sedative effect. It exerts its effect rapidly and has a high plasma clearance rate and a short duration of action. Propofol, at the target plasma concentration of 0.2-2 $\mu \mathrm{g} /$ $\mathrm{mL}$ combined with small doses of opioids, can meet the sedation needs of patients in the intensive care unit (ICU) and during cardiac surgery (McMurray et al., 2004). When the target concentration is $2.12-3.37 \mu \mathrm{g} / \mathrm{mL}$, propofol can produce excellent sedation in healthy volunteers (Haenggi et al., 2004). Therefore, propofol is often used for ICU sedation, and for general anesthesia and during palinesthesia (Blayney et al., 2003; McMurray et al., 2004). Remifentanil, an immediate effective opioid analgesic, can be rapidly hydrolyzed by nonspecific esterases in blood and tissues. It exerts its effect rapidly, and its half-life in plasma is constant and very short, regardless of the infusion time. After discontinuation, patients can quickly regain consciousness. It has been widely used in clinical anesthesia (Hughes et al., 1992; Kapila et al., 1995; Soltesz et al., 2001). Recent studies have shown that the use of remifentanil can benefit patients who are awake (Shajar et al., 1999; Wilhelm et al., 2001; Hohlrieder et al., 2007). The purpose of this study was to investigate the effect of maintaining an intravenous infusion of remifentanil or propofol on the performance of general anesthesia, including the cardiovascular response, choking, and irritability at the end of general anesthesia, in order to assess the effect of a maintenance intravenous infusion of remifentanil or propofol. 


\section{MATERIAL AND METHODS}

\section{Subjects}

From March 2010 to August 2010, according to quality clinical practice guidelines, after the patients had signed the informed consent, we studied 60 patients with elective lower esophageal resection, aged 40 to 65 years old, ASA I-II, body mass index (BMI) $23-28 \mathrm{~kg} / \mathrm{m}^{2}$.

The exclusion criteria included a history of hypertension, cardiovascular disease, asthma, chronic obstructive pulmonary disease, difficult airways, perioperative aspiration risk factors, chronic cough, and recent respiratory tract infection history.

All patients underwent a preoperative intramuscular injection of penehyclidine hydrochloride at $0.01 \mathrm{mg} / \mathrm{kg}$. Anesthesia was induced with intravenous propofol at $2 \mathrm{mg} / \mathrm{kg}$, fentan$\mathrm{yl}$ at $3-5 \mu \mathrm{g} / \mathrm{kg}$, and atracurium at $0.6 \mathrm{mg} / \mathrm{kg}$ to obtain satisfactory neuromuscular conditions, and endotracheal intubation was performed. Atracurium at $0.3 \mathrm{mg} \cdot \mathrm{kg}^{-1} \cdot \mathrm{h}^{-1}, 0.5-1$ minimum alveolar concentration (MAC) inhaled sevoflurane, remifentanil at 1-4 $\mathrm{ng} / \mathrm{mL}$, and propofol at $1-4 \mu \mathrm{g} / \mathrm{mL}$ were used intraoperatively and target-controlled infused to maintain anesthesia (propofol infusion model, Marsh; remifentanil infusion model, Minto). The blood pressure and heart rate fluctuations were maintained within a range of $10 \%$ during surgery by adjusting the target concentration of propofol and remifentanil. During surgery, end-tidal carbon dioxide partial pressure $\left(\mathrm{PETCO}_{2}\right)$ and bispectral index (BIS) values were monitored to maintain $\mathrm{PETCO}_{2}$ at $35-45 \mathrm{mmHg}(1 \mathrm{mmHg}=0.133 \mathrm{kPa})$ and BIS values at $35-50$.

At the end of surgery, all patients stopped all drugs, oropharynx and endotracheal suctioning was performed with a simple breathing bag, and patients were quickly sent to the anesthesia recovery room. The patients received mechanical ventilation by a breathing machine with the fresh gas flow set to $2 \mathrm{~L} / \mathrm{min}$. The electrocardiograms, blood pressure, heart rate, $\mathrm{PETCO}_{2}$, pulse oximetry, exhaled gas sevoflurane concentration, and BIS values of the patients were monitored, and a peripheral nerve stimulator was used to monitor the recovery of muscle function with four clusters of stimulation. In the recovery room, according to computer sorting, patients were randomly divided into three groups: the control group, the remifentanil group, and the propofol ( $\mathrm{N}=20$ per group). In the control group, patients waited for extubation; in the remifentanil group, a target controlled infusion of remifentanil was given with a target plasma concentration of $3 \mathrm{ng} / \mathrm{mL}$; in the propofol group, a target controlled infusion of propofol was given with a plasma target concentration of $2 \mu \mathrm{g} / \mathrm{mL}$. When the blood pressure and heart rate (HR) fluctuation of the patients surpassed $20 \%$ of the baseline values, vasoactive drugs were used for symptomatic treatment. When TOF $>0.75$ and exhaled gas concentrations of sevoflurane $<0.1$ MAC, remifentanil or propofol were stopped, and the response of the patients was observed while waiting for extubation. Extubation criteria included breathing frequency $>10 /$ min, tidal volume $>6 \mathrm{~mL} / \mathrm{kg}$, inhalation of air under the conditions of $\mathrm{SpO}_{2}>90 \%, \mathrm{PETCO}_{2}$ wave rules and a partially restored swallowing reflex.

The mean arterial pressure (MAP), HR, and BIS values of the three groups were recorded at the end of surgery $\left(\mathrm{T}_{0}\right)$, the time when the patients entered the recovery room $\left(\mathrm{T}_{1}\right)$, when TOF $>0.75$ and the exhaled gas sevoflurane concentration $<0.1$ MAC time $\left(T_{2}\right)$, extubation $\left(\mathrm{T}_{3}\right), 1$ min after removing the tube $\left(\mathrm{T}_{4}\right)$, and $5 \mathrm{~min}$ after extubation $\left(\mathrm{T}_{5}\right)$. In the recovery room, time $(\mathrm{t}, \mathrm{min})$ represented the time interval $\mathrm{T}_{0}$ to $\mathrm{T}_{1}$. Extubation time $(\mathrm{T}, \mathrm{min})$ represented the time interval from $T_{0}$ to $T_{3}$. A five-grade scoring scheme was used to evaluate the extuba- 
tion response of the patients: $1=$ no cough and muscle rigidity; $2=$ mild cough; $3=$ moderate cough; $4=$ moderate cough or muscle rigidity; and $5=$ agitation, cannot be extubated (Minogue et al., 2004). A five-grade scoring scheme was adopted to evaluate nausea and vomiting in patients: 0 . no nausea and vomiting; $1=$ mild nausea but does not need treatment; $2=$ antiemetic agents can control nausea; 3 = antiemetic agents can control vomiting; and $4=$ antiemetic treatment cannot control nausea and vomiting (Nho et al., 2009). The Steward score can be used to assess the response of patients after extubation, including: the level of consciousness (score of 2 $=$ fully awake, $1=$ have response to stimuli, $0=$ no response to stimuli), degree of unobstructed airway (score of $2=$ coughing according to the physician; $1=$ unobstructed airway maintained without support, $0=$ respiratory tract needs to be supported), and physical activity (score of 2 $=$ physical activity of the patients can be consciously performed; $1=$ physical activity of the patients can be unconsciously performed; $0=$ no physical activity). Patients could leave the recovery room after anesthesia with a score of 4 or more. In the anesthesia recovery room, doctors and nurses did not know the grouping, the anesthesiologists were responsible for extubation and determining the associated score (extubation response rate, nausea and vomiting score, and Steward score), and the nurses were responsible for recording data.

\section{Statistical analysis}

All data were analyzed with the SPSS 13.0 statistical software. All measurements are reported as means \pm standard deviation (SD). The comparison of the parameters at different time points between groups was done by the Student $t$-test, ANOVA was used to compare between groups, the q-test was used to compare population means between groups, and count data were evaluated by the chi-square test. $\mathrm{P}<0.05$ was considered to represent a statistically significant difference.

\section{RESULTS}

In this investigation, 65 patients were recruited, and 60 patients were enrolled in and finished the study, in which the patients were divided into a control group, remifentanil group, and propofol group ( $\mathrm{N}=20$ per group).

As shown in Table 1, the gender, age, height, and BMI of the patients in the three groups were not different. At the time at which the patients in the three groups were transferred to the recovery room, the nausea and vomiting scores were not significantly different $(\mathrm{P}>0.05)$. The incidence of cough and muscle rigidity in the patients in the remifentanil and propofol groups was significantly lower than in the control group $(\mathrm{P}<0.05)$. The extubation time of the patients in the propofol group was significantly longer than that of the patients in the remifentanil and control groups $(\mathrm{P}<0.05)$.

As shown in Table 2, during analepsia, when compared with values at $\mathrm{T}_{0}$, the $\mathrm{HR}$ and MAP of the patients in the control group were increased at $\mathrm{T}_{2-5}(\mathrm{P}<0.05$ or 0.01$)$. The HR and MAP of the patients in the remifentanil and propofol groups were increased at $\mathrm{T}_{3}$ and $\mathrm{T}_{4}(\mathrm{P}<$ 0.05). Compared with that of the patients in the remifentanil and propofol groups, the MAP of the patients in the control group were increased significantly at $\mathrm{T}_{3}$ and $\mathrm{T}_{4}$, and the HR of the patients in the control group were significantly increased at $\mathrm{T}_{2-4}(\mathrm{P}<0.05)$. There were no significant differences in MAP and HR in the patients in the remifentanil and propofol groups 
at each time point. The BIS values of the patients in the three groups were gradually increased. At $T_{2}$, patients in the remifentanil group were fully awake, while some patients in the control and propofol groups were still in a state of drowsiness or confusion. The BIS values of the patients in the remifentanil group were significantly higher than those of the patients in the propofol group at $\mathrm{T}_{3}$ and $\mathrm{T}_{4}(\mathrm{P}<0.05)$.

Table 1. Comparison of the gender, age, height, body mass index, time to extubation, extubation reactions, nausea, vomiting and Steward scores of the patients in the three groups $(\mathrm{N}=20$ per group).

\begin{tabular}{lccc}
\hline & C group & R group & P group \\
\hline Gender (male/female) & $12 / 8$ & $10 / 10$ & $11 / 9$ \\
Age (years) & $53 \pm 13$ & $54 \pm 11$ & $52 \pm 12$ \\
Body height (cm) & $168 \pm 11$ & $169 \pm 13$ & $167 \pm 12$ \\
Body mass index $\left(\mathrm{kg} / \mathrm{m}^{2}\right)$ & $26.1 \pm 2.8$ & $25.8 \pm 2.7$ & $26.3 \pm 2.9$ \\
Time of entering analepsia room (t, min) & $2.0 \pm 0.3$ & $2.1 \pm 0.4$ & $2.0 \pm 0.4$ \\
Extubate time $(\mathrm{T}, \mathrm{min})$ & $14.5 \pm 2.4$ & $16.7 \pm 2.9$ & $21.4 \pm 3.7^{\mathrm{ab}}$ \\
Extubate reaction $(1 / 2 / 3 / 4 / 5)$ & $2 / 11 / 6 / 1 / 0$ & $11 / 8 / 1 / 0 / 0^{\mathrm{a}}$ & $9 / 9 / 2 / 0 / 0^{\mathrm{a}}$ \\
Nausea and vomiting score $(1 / 2 / 3 / 4 / 5)$ & $16 / 2 / 2 / 0 / 0$ & $18 / 2 / 0 / 0 / 0$ & $17 / 2 / 1 / 0 / 0$ \\
Extubate Steward score & $14 / 6 / 0$ & $20 / 0 / 0^{\mathrm{a}}$ & $13 / 7 / 0^{\mathrm{b}}$ \\
Consciousness (2/1/0) & $13 / 7 / 0$ & $20 / 0 / 0^{\mathrm{a}}$ & $18 / 2 / /^{\mathrm{a}}$ \\
Unobstructed respiratory passage (2/1/0) & $14 / 6 / 0$ & $20 / 0 / 0^{\mathrm{a}}$ & $15 / 5 / 0^{\mathrm{b}}$ \\
\hline Extremity activity (2/1/0) & & \\
\hline
\end{tabular}

$\mathrm{C}=$ control group; $\mathrm{R}=$ remifentanil group; $\mathrm{P}=$ propofol group. $\mathrm{P}<0.05$ compared with the $\mathrm{C}$ group; $\mathrm{P}<0.05$ compared with the $\mathrm{R}$ group.

\begin{tabular}{|c|c|c|c|c|c|c|}
\hline & $\mathrm{T}_{0}$ & $\mathrm{~T}_{1}$ & $\mathrm{~T}_{2}$ & $\mathrm{~T}_{3}$ & $\mathrm{~T}_{4}$ & $\mathrm{~T}_{5}$ \\
\hline \multicolumn{7}{|c|}{ MAP (mmHg) } \\
\hline $\mathrm{C}$ & $97 \pm 11$ & $102 \pm 13$ & $113 \pm 14^{c}$ & $135 \pm 23^{c}$ & $129 \pm 19^{c}$ & $115 \pm 16^{\circ}$ \\
\hline $\mathrm{R}$ & $99 \pm 12$ & $103 \pm 11$ & $106 \pm 11$ & $117 \pm 14^{\mathrm{cd}}$ & $114 \pm 13^{\mathrm{cd}}$ & $107 \pm 12$ \\
\hline $\mathrm{P}$ & $98 \pm 11$ & $103 \pm 12$ & $105 \pm 12$ & $119 \pm 17^{c d}$ & $113 \pm 13^{\text {cd }}$ & $106 \pm 11$ \\
\hline \multicolumn{7}{|c|}{ HR (bpm) } \\
\hline $\mathrm{C}$ & $62 \pm 7$ & $67 \pm 9$ & $84 \pm 13^{c}$ & $102 \pm 19^{c}$ & $97 \pm 16^{\mathrm{c}}$ & $85 \pm 13^{\circ}$ \\
\hline $\mathrm{R}$ & $61 \pm 7$ & $65 \pm 8$ & $67 \pm 9^{d}$ & $85 \pm 13^{\mathrm{cd}}$ & $80 \pm 12^{\mathrm{cd}}$ & $77 \pm 10^{c}$ \\
\hline$P$ & $63 \pm 8$ & $66 \pm 8$ & $69 \pm 10^{\mathrm{d}}$ & $86 \pm 15^{\text {cd }}$ & $82 \pm 12^{\text {cd }}$ & $78 \pm 11^{\circ}$ \\
\hline \multicolumn{7}{|l|}{ BIS } \\
\hline $\mathrm{C}$ & $42 \pm 4$ & $50 \pm 7$ & $70 \pm 9^{c}$ & $78 \pm 11^{\mathrm{c}}$ & $79 \pm 13^{c}$ & $86 \pm 12^{\circ}$ \\
\hline $\mathrm{R}$ & $43 \pm 5$ & $52 \pm 8$ & $67 \pm 8^{c}$ & $85 \pm 9^{c}$ & $87 \pm 10^{c}$ & $89 \pm 9^{c}$ \\
\hline $\mathrm{P}$ & $42 \pm 5$ & $51 \pm 7$ & $60 \pm 6^{c}$ & $69 \pm 7^{\mathrm{ce}}$ & $72 \pm 9^{\text {ce }}$ & $80 \pm 10^{c}$ \\
\hline
\end{tabular}

Data are reported as means $\pm \mathrm{SD} . \mathrm{C}=$ control group; $\mathrm{R}=$ remifentanil group; $\mathrm{P}=$ propofol group. ${ }^{\mathrm{c}} \mathrm{P}<0.05$ compared with $\mathrm{T}_{0}$; ${ }^{\mathrm{d}} \mathrm{P}<0.05$ compared with the $\mathrm{C}$ group; ${ }^{\mathrm{e}} \mathrm{P}<0.05$ compared with the $\mathrm{R}$ group.

\section{DISCUSSION}

Maintaining intravenous infusion of remifentanil or propofol can lessen the cardiovascular response, choking, and irritability that occur upon removing the endotracheal tube during palinesthesia after administration of general anesthesia. Studies have reported that during the analepsia of general anesthesia, and with the regression of the effect of narcotic drugs and the recovery of pain and sense, the patient will gradually feel pain and discomfort. If the patient is not handled properly at this time, and is stimulated by extubation, this can easily cause a high dynamic response of the circulatory system, throat spasms, delirium or agitation, and may even threaten the life and safety of the patient (Leech et al., 
1974; Plafreman and Wakeling, 2002; Irwin, 2006). Therefore, it is particularly important to select an appropriate method or treatment during recovery to ensure that patients survive the recovery period following general anesthesia and undergo a smooth extubation process. In order to prevent a high dynamic response and choking in the recovery process of general anesthesia and extubation, many methods, such as deep anesthesia extubation, the use of local anesthetics, vasodilators, short-acting opioiddrugs, and othermethods, have beenused in the clinic (Shajar et al., 1999; Hohlrieder et al., 2007). Studies have reported that the application of general anesthesia with propofol or remifentanil could make the recovery process of patients smoother (Shajar et al., 1999; Wilhelm et al., 2001; Blayney et al., 2003; Hohlrieder et al., 2007). However, propofol and remifentanil, which are more conducive to allowing patients to pass through the recovery period safely, have been less characterized. In order to objectively evaluate the effects of these two drugs, the anesthetic management of the patients during surgery was identical. Propofol, a short-acting intravenous anesthetic, has high liposolubility. It induces rapidly analepsia, does not accumulate even with continuous infusion, and its metabolic products have no pharmacological activity. It has been widely used for the induction and maintenance of general anesthesia in the clinic. McMurray et al. (2004) reported that propofol at a target concentration of $0.2-2 \mu \mathrm{g} / \mathrm{mL}$ in plasma, combined with small doses of opioids, can meet the sedation needs of patients in the ICU and in cardiac surgery patients. Haenggi et al. (2004) reported that propofol at a target concentration of $2.12-3.37 \mu \mathrm{g} / \mathrm{mL}$ in plasma can produce excellent sedation in healthy volunteers. Propofol at sleep-inducing concentrations can dose-dependently inhibit the airway response (Guglielminotti et al., 2005). As this was an intraoperative study, propofol and remifentanil were continued until the end of surgery. There were residual effects of the drugs during extubation, so we chose propofol at a target plasma concentration of $2 \mu \mathrm{g} / \mathrm{mL}$ for the infusion. Further studies are still needed to determine the ideal dose of propofol to facilitate patient recovery from anesthesia. These results indicate that the hemodynamics of patients in the propofol group during analepsia after extubation were more stable than those of patients in the control group. There were no significant differences when compared with the response of the patients in the remifentanil group, but the extubation time was significantly longer than that of the patients in the control and remifentanil groups. The level of consciousness of the patients in the propofol group was poorer than that of the patients in the remifentanil group. This shows that an intravenous infusion of propofol can make the analepsic process of patients smoother during analepsia after anesthesia and reduce the incidence of the dynamic response, bucking and muscle rigidity during the recovery period, but will prolong the retention time of patients in the recovery room.

Remifentanil, as an immediately effective opioid analgesic, can be rapidly hydrolyzed by non-specific esterases in blood and tissue. It exerts its effect rapidly and the half-life in plasma is constant and very short regardless of infusion time. Its elimination half-life is 3-5 min (Hughes et al., 1992; Kapila et al., 1995; Soltesz et al., 2001). It has been reported (Soltesz et al., 2001; Albertin et al., 2005, 2006) that remifentanil, combined with other anesthetics at a target concentration of $1-3 \mathrm{ng} / \mathrm{mL}$ in the plasma, can inhibit the sympathetic response in $50 \%$ of patients when the skin is incised. A target concentration of $4 \mathrm{ng} / \mathrm{mL}$ remifentanil is required for intubation, and the target concentration is maintained at $2-5 \mathrm{ng} / \mathrm{mL}$ during surgery. As all narcotic drugs were continued until the end of surgery in this study, we considered that remifentanil at $3 \mathrm{ng} / \mathrm{mL}$ in plasma, combined with the residual effects of the anesthetic agents, should allow the patients to tolerate tracheal intubation, so we chose $3 \mathrm{ng} / \mathrm{mL}$ as the target plasma 
concentration. However, the ideal dose of remifentanil still needs to be determined during recovery from anesthesia. These results show that the BIS values of the patients in the remifentanil group were gradually increased. Extubation occurred when all the patients were awake and had stable hemodynamics, and this intervention did not extend the time of extubation. With the emergence of new technology and new drugs, the anesthesiologist can unhurriedly face many adverse events with the use of lidocaine, esmolol, dilthiazem, verapamil, and opioids to treat hypertension, tachycardia, and heart disorders during extubation (Steinhaus and Gaskin, 1963; Kern et al., 1990; De Castro et al., 2003). The intravenous administration of butorphanol tartrate or nefopam hydrochloride can treat shivering caused for various reasons after anesthesia (Juneja et al., 1992; Yarmush et al., 1997; Piper et al., 2004). The intravenous injection of a highly selective 5- $\mathrm{HT}_{3}$ receptor antagonist can symptomatically treat nausea and vomiting (Goodin and Cunningham, 2002). While no specific drug can treat restlessness and delirium, sedative hypnotics have been used in the clinic to deepen anesthesia and suppress agitation and delirium, and thus can prolong the reflex recovery time during the protection period. This can significantly increase the incidence of adverse events including delayed recovery, airway obstruction, aspiration asphyxia, and hemodynamic fluctuations. When extubating, remifentanil can be used to keep the patient awake without delirium, laryngospasm, aspiration, and asphyxia. This drug, combined with vasoactive drugs, can stabilize hemodynamics and avoid the occurrence of adverse events to the greatest extent during extubation.

Maintaining an intravenous infusion of remifentanil or propofol can lessen the hemodynamic response, choking and irritability that occur during palinesthesia after administration of general anesthesia while removing the endotracheal tube. The patients in the remifentanil group were fully awake when extubating, and remifentanil intervention did not extend the recovery time. Therefore, a maintenance infusion of remifentanil during general anesthesia may be a better choice.

\section{REFERENCES}

Albertin A, Casati A, Federica L, Roberto V, et al. (2005). The effect-site concentration of remifentanil blunting cardiovascular responses to tracheal intubation and skin incision during bispectral index-guided propofol anesthesia. Anesth. Analg. 101: 125-30.

Albertin A, Dedola E, Bergonzi PC, Lombardo F, et al. (2006). The effect of adding two target-controlled concentrations (1-3 $\left.\mathrm{ng} \mathrm{mL}^{-1}\right)$ of remifentanil on MAC BAR of desflurane. Eur. J. Anaesthesiol. 23: 510-516.

Blayney MR, Ryan JD and Malins AF (2003). Propofol target-controlled infusions for sedation - a safe technique for the non-anaesthetist? Br. Dent. J. 194: 450-452.

De Castro V, Godet G, Mencia G, Raux M, et al. (2003). Target-controlled infusion for remifentanil in vascular patients improves hemodynamics and decreases remifentanil requirement. Anesth. Analg. 96: 33-38, table.

Goodin S and Cunningham R (2002). 5-HT(3)-receptor antagonists for the treatment of nausea and vomiting: a reappraisal of their side-effect profile. Oncologist 7: 424-436.

Guglielminotti J, Rackelboom T, Tesniere A, Panhard X, et al. (2005). Assessment of the cough reflex after propofol anaesthesia for colonoscopy. Br. J. Anaesth. 95: 406-409.

Haenggi M, Ypparila H, Takala J, Korhonen I, et al. (2004). Measuring depth of sedation with auditory evoked potentials during controlled infusion of propofol and remifentanil in healthy volunteers. Anesth. Analg. 99: 1728-1736.

Hohlrieder M, Tiefenthaler W, Klaus H, Gabl M, et al. (2007). Effect of total intravenous anaesthesia and balanced anaesthesia on the frequency of coughing during emergence from the anaesthesia. Br. J. Anaesth. 99: 587-591.

Hughes MA, Glass PS and Jacobs JR (1992). Context-sensitive half-time in multicompartment pharmacokinetic models for intravenous anesthetic drugs. Anesthesiology 76: 334-341.

Irwin RS (2006). Complications of cough: ACCP evidence-based clinical practice guidelines. Chest 129: 54S-58S.

Juneja M, Ackerman WE III, Heine MF, Cases-Cristobal V, et al. (1992). Butorphanol for the relief of shivering associated with extradural anesthesia in parturients. J. Clin. Anesth. 4: 390-393. 
Kapila A, Glass PS, Jacobs JR, Muir KT, et al. (1995). Measured context-sensitive half-times of remifentanil and alfentanil. Anesthesiology 83: 968-975.

Kern MJ, Gudipati C, Tatineni S, Aguirre F, et al. (1990). Effect of abruptly increased intrathoracic pressure on coronary blood flow velocity in patients. Am. Heart J. 119: 863-870.

Leech P, Barker J and Fitch W (1974). Proceedings: Changes in intracranial pressure and systemic arterial pressure during the termination of anaesthesia. Br. J. Anaesth. 46: 315-316.

McMurray TJ, Johnston JR, Milligan KR, Grant IS, et al. (2004). Propofol sedation using Diprifusor target-controlled infusion in adult intensive care unit patients. Anaesthesia 59: 636-641.

Minogue SC, Ralph J and Lampa MJ (2004). Laryngotracheal topicalization with lidocaine before intubation decreases the incidence of coughing on emergence from general anesthesia. Anesth. Analg. 99: 1253-7.

Nho JS, Lee SY, Kang JM, Kim MC, et al. (2009). Effects of maintaining a remifentanil infusion on the recovery profiles during emergence from anaesthesia and tracheal extubation. Br. J. Anaesth. 103: 817-821.

Piper SN, Röhm KD, Suttner SW, Maleck WH, et al. (2004). A comparison of nefopam and clonidine for the prevention of postanaesthetic shivering: a comparative, double-blind and placebo-controlled dose-ranging study. Anaesthesia 59: 559-564.

Plafreman TM and Wakeling HG (2002). Attenuation of cardiovascular and cough reflexes during extubation. Anaesthesia 57: 1034-1035.

Shajar MA, Thompson JP, Hall AP, Leslie NA, et al. (1999). Effect of a remifentanil bolus dose on the cardiovascular response to emergence from anaesthesia and tracheal extubation. Br. J. Anaesth. 83: 654-656.

Soltesz S, Biedler A, Silomon M, Schopflin I, et al. (2001). Recovery after remifentanil and sufentanil for analgesia and sedation of mechanically ventilated patients after trauma or major surgery. Br. J. Anaesth. 86: 763-768.

Steinhaus JE and Gaskin L (1963). A study of intravenous lidocaine as a suppressant of cough reflex. Anesthesiology 24: 285-290.

Wilhelm W, Schlaich N, Harrer J, Kleinschmidt S, et al. (2001). Recovery and neurological examination after remifentanildesflurane or fentanyl-desflurane anaesthesia for carotid artery surgery. Br. J. Anaesth. 86: 44-49.

Yarmush J, D'Angelo R, Kirkhart B, O’Leary C, et al. (1997). A comparison of remifentanil and morphine sulfate for acute postoperative analgesia after total intravenous anesthesia with remifentanil and propofol. Anesthesiology 87: $235-243$ 